\title{
Assessment of The Effect of Pyridoxine
}

Hydrochloride Supplementation on Anthropometric Measurements, Body Composition, Visceral Adiposity Index And Metabolic Status In Obese and Overweight Women

\section{Fatemeh Haidari}

Ahvaz Jundishapur University of Medical Sciences

Majid Mohammadshahi

Ahvaz Jundishapur University of Medical Sciences

Mehdi Zarei

Shahid Chamran University of Ahvaz

Mohammad Hosein Haghighizadeh

Ahvaz Jundishapur University of Medical Sciences

Fatemeh Mirzaee ( $\sim$ faribamirzaey@gmail.com )

Ahvaz Jundishapur University of Medical Sciences

\section{Research}

Keywords: vitaminB6, body composition, adipocytokine, glycemic indices, lipid profile, excessive body weight.

Posted Date: March 8th, 2021

DOl: https://doi.org/10.21203/rs.3.rs-39317/v2

License: (c) (i) This work is licensed under a Creative Commons Attribution 4.0 International License.

Read Full License 


\section{Abstract}

Background and Objectives: Obesity has reached epidemic proportions globally. Among several methods for treating obesity, the use of dietary supplements is common recently. One supplement that can help in this regard might be vitamin B6 in high doses. The objective of this study was to evaluate the efficacy of pyridoxine hydrochloride supplementation on anthropometric measurements, body composition, visceral adiposity index and metabolic status in obese and overweight women.

Methods and Study Design: In this randomized controlled clinical trial, 44 obese and overweight women aged 18-50 years were selected and divided randomly into two groups: an intervention group (receiving 80 mg pyridoxine hydrochloride supplement for 8 weeks) and control group (receiving placebo for 8 weeks).

Results: In the pyridoxine hydrochloride group, weight $(p=0.01)$, body mass index $(p=0.009)$, fat mass $(p=0.003)$, waist circumference $(p=0.005)$, visceral adiposity index $(p=0.001)$, fasting insulin, Insulin Resistance(HOMA-IR), Total cholesterol, low density lipoprotein(LDL), Triglycerides (TG) and leptin $(p<0.001)$ decreased whereas adiponectin $(p<0.001)$ increased in comparison to the baseline values. There was a significant difference in fat mass, visceral adiposity index, fasting insulin, HOMA-IR and TG between pyridoxine hydrochloride and control groups following intervention in adjusted models $(p<0.05)$.

Conclusions: The findings suggest that vitamin B6 supplementation may be effective in reducing BMI and improving body composition and biochemical factors associated with obesity.

Trial registration: Iran Clinical Trials Registry: IRCT20181002041206N1. Registered on 31 October 2018, https://en.irct.ir/trial/34220.

\section{Background:}

Abnormal or excessive fat accumulation in the body is defined as overweight and obesity, which may affect on health status. In 2016, more than 1.9 billion adults aged 18 years and older were overweight. Of these over 650 million adults were obese (1). Genetic factors, sedentary life style, mild inflammation in the body, the consumption of certain medications, some diseases, the lack of balance between calories intake and calories consumed, sleep deprivation or stress are all known factors associated with obesity (2). Obesity is related with chronic disease, such as cardiovascular disease, diabetes, hypertension, stroke, musculoskeletal disorders and some cancers $(1,3)$. There are several strategies to weight loss including adequate physical activity, weight loss medications, and various types of obesity surgery (4). Since drug therapy and surgeries are accompany with various side effects, using natural or synthetic dietary supplements has attracted the attention of researchers.

Vitamin B6 is one of the water-soluble vitamins. There are three forms of Vitamin B6: pyridoxamine (PM), pyridoxal (PL), and pyridoxine (PN) (5). Deficiency of this vitamin is rare because it is abundant in food sources. The maximum amount of this vitamin is found in meat, whole grains, vegetables and nuts. 
Beside dietary source, the gut microbiota is an important source of vitamin B6 production in the colon(6).Vitamin B6 acts as an important coenzyme in various reactions in the body, including: metabolism of amino acids, glucose release from glycogen, modulation and regulation of steroid hormone receptors, tryptophan conversion to niacin and Biosynthesis of sphingolipids (6). It is also played a role in the biosynthesis of dopamine, serotonin and gammaaminobutyric acid neurotransmitters that regulate various functions like blood pressure, mental state and depression and appetite(7-9).In some studies the effects of pyridoxine on calcium ion signaling have been observed that increases lipolysis and decreases fatty acid synthesis(10-12). In some studies, it has also been shown to decrease insulin resistance (13-16) and improved lipid profile $(13,17-19)$. The antioxidant $(20)$ and antiinflammatory (15) effects of this vitamin are also seen. The effect of different forms of vitamin B6 administration on mice has been shown to decrease significantly in Body and adipose tissue weight(21), fasting blood glucose $(13,22)$, liver triglyceride and cholesterol levels and hepatic lipid accumulation (13), fasting insulin levels and increase insulin sensitivity $(3,14)$ in previous studies.

Since the effect of oral pyridoxine hydrochloride (vitamin B6) supplementation on weight loss in obese and overweight subjects has not been studied, the current study was aimed to evaluate the effect of oral pyridoxine hydrochloride supplement on anthropometric measurements, body composition, visceral adiposity index, glycemic and lipidemic risk factors and serum levels of leptin and adiponectin in obese and overweight women.

\section{Methods:}

This randomized, double-blind, placebo-controlled clinical trial included 44 obese and overweight women. The trial was approved by the Ethics Committee of Ahvaz Jundishapur University of Medical Sciences (reference number: ir.ajums.rec.1394.254) and registered in the registration center for clinical trials in Iran (code: IRCT20181002041206N1).Initial anthropometric measurements, namely the weight, height, waist circumference (WC), and waist-to-hip circumference ratio (WHR), were recorded. Inclusion criteria were age range of 18-50 years, body mass index (BMI) equal to or higher than $25 \mathrm{~kg} / \mathrm{m} 2$ and patient satisfaction. Exclusion criteria included pregnancy; lactation; menopause; smoking; alcohol and drug abuse; participation in exercise or weight reduction programs; medications known to affect weight in the past six months; history or presence of other diseases such as diabetes, cardiovascular diseases, hypertension, and infection; other inflammatory disorders; liver and kidney disorders; steroids or hormonal drugs; and the consumption of vitamins and minerals in the past six months.

\section{Study Design:}

This study investigated the effect of $80 \mathrm{mg}$ pyridoxine hydrochloride supplement on anthropometric measurements, body composition, visceral adiposity index, glycemic and lipidemic risk factors and serum levels of leptin and adiponectin in obese and overweight women. Patients were recruited from Jundishapur University of Medical Science, in Ahvaz, Iran, in 2019. After explaining the projects, we 
requested each participating patient to complete the consent form. Enrolled patients were divided into two groups by randomized block allocation using random number table. Randomization and allocated number to each group was performed by an independent consultant statistician. The participants in intervention group received $80 \mathrm{mg}$ pyridoxine hydrochloride (Two $40 \mathrm{mg}$ tablets) per day for 8 weeks whereas participants in control group received matching starch tablets. Pyridoxine hydrochloride supplement were Purchased from pharmacy and placebo tablets were manufactured by Pharmaceutical Incubator, Jundishapur University of Medical Science (Ahvaz, Iran). On the basis of randomized block allocation, pyridoxine hydrochloride and placebo tablets were distributed to the persons by research assistants who were not aware of group allocation. Data collectors, interviewers and principal investigators were not aware of the patient allocation during the intervention period. Patients were followed biweekly by telephone during the study. Participant's compliance to the treatment was calculated by counting the number of remaining tablets at the end of the study. If more than $10 \%$ of prescribed tablets were not consumed, the patient was excluded. Patient recruitment flowchart for this clinical trial is presented in Fig. 1.The diet was recorded before, during, and at the end of the study by using 3-day food recall, namely one weekend day and two weekdays, to assess their total energy and macronutrient intake. We asked participants not to change their level of physical activity during the study. International physical activity questionnaire (IPAQ) was used to assess physical activity. Data from the IPAQ were converted to metabolic equivalent (MET)-minutes/week by using the existing guidelines (23). Demographic information and medical history were recorded for each participant, and anthropometric measurements including weight (use of BF511-Omron body composition monitor) and height were recorded, and the BMI $(\mathrm{kg} / \mathrm{m} 2)$ was calculated. The height was measured using a non-stretchable tape to the nearest $0.5 \mathrm{~cm}$ while standing barefoot with heels sticking to the wall, head straightened, and eyes looking forward. The weight was measured with minimum clothing by using a BF511-Omron body composition monitor. The body composition was also measured with this device. Subsequently, the body mass index (BMI) and visceral adiposity index (VAI) were determined using the formulae $\mathrm{BMI}=$ weight in

kilograms divided by the square of the height in meters and

$$
\mathrm{VAI}=\left(\frac{\mathrm{WC}}{36.58+(1.89 \times \mathrm{BMI})}\right) \times\left(\frac{\mathrm{TG}}{0.81}\right) \times\left(\frac{1.52}{\mathrm{HDL}-\mathrm{C}}\right)
$$

(24). Visceral fat was measured using the visceral fat index and suggested as a valid indicator of visceral fat performance.

\section{Biochemical Analysis:}

At the beginning and at the end of the study, blood samples were collected from all participants after 1214 hour overnight fasting. Serum samples were prepared then frozen and stored at $-70^{\circ} \mathrm{C}$ until used for biochemical testing. The parameters were FBS, total cholesterol, low- and high density lipoprotein (LDL and $H D L$, respectively), triglyceride (TG), serum insulin, leptin and adiponectin. Serum glucose, TG, and total and HDL cholesterol were measured using the enzymatic method. LDL cholesterol was calculated using the Friedewald formula [total cholesterol - (HDL + TG/5)] (25). Serum insulin was measured using an enzyme linked immune sorbent assay (ELISA) test kit (Diaplus, Canada), and the homoeostasis model assessment of insulin resistance was calculated using the following formula: fasting plasma glucose 
$(\mathrm{mmol} / \mathrm{L}) \times$ fasting insulin $(\mu \mathrm{U} / \mathrm{mL}) / 22.5(26)$. Serum leptin was measured using a leptin ELISA test kit (Diagnostics Biochem Canada Inc, London, ON, Canada). For quantitatively detecting human adiponectin in samples, we used a human adiponectin ELISA test kit (Boster Biological Technology, USA).

\section{Statistical analysis:}

SPSS software version 22 was used for statistical analysis of data. We used Kolmogorov-Smirnov test to determine normality for all quantitative data. Mann-Whitney $\mathrm{U}$ test and Wilcoxon's signature ranking test were used as non-parametric options to compare sample parameters at the beginning and at the end of the study, respectively, between and within groups. Univariate ANCOVA was used for adjustment of potential confounding variables, namely the energy intake (kcal/day), Weight ( $\mathrm{kg}), \mathrm{BMI}(\mathrm{kg} / \mathrm{m} 2)$, and physical activity level (MET-minutes/week). In describing the data we use mean and standard deviation (mean \pm standard). The differences were statistically significant at $p<0.05$. In this study, the diet was analyzed using a Nutritionist IV (First Databank, San Bruno, CA, USA), which was modified for Iranian foods.

\section{Results:}

Demographic and anthropometric characteristics of the participants at the baseline and the end of the study have been presented in Table 1.The results of this information show no significant differences between the two groups in the beginning of the study $(P>0.05)$. There were no significant changes in $\mathrm{BMI}$, weight, Muscle mass, WC, WHR, visceral adiposity index and physical activity in the subjects after consuming of pyridoxine hydrochloride and placebo (Table 1).

At the end of the study, we just observed significantly decreased in fat mass between the two groups $(P=$ 0.02). Of course after adjustments for weight, $B M I$, energy intake and physical activity levels, fat mass ( $P$ $<0.001)$ and visceral adiposity index $(P=0.03)$.

In the intervention group Weight $(p=0.01), \mathrm{BMI}(\mathrm{p}=0.009)$, Fat mass $(p=0.003), W C(p=0.005)$ and visceral adiposity index $(p=0.001)$ decreased significantly after eight weeks. The Placebo group showed no significant change after eight weeks $(P>0.05)$.

Table 2 shows macronutrients intake and dietary vitamin B6 in two groups. No significant change was observed in these variables between two groups at baseline, during and the end of study $(P>0.05)$.

Tables 3 and 4 show the biochemical indices in the beginning and at the end of the study in the two groups. There was no significant difference in FBS, fasting insulin, Insulin resistance index (HOMA-IR), lipid profile (triglyceride, total cholesterol, LDL-C, HDL-C), leptin and adiponectin between the two groups at baseline $(P>0.05)$. 
At the end of the study, we observed significant reduction in fasting insulin $(P<0.001)$, HOMA-IR $(P<$ $0.001)$, total cholesterol $(P=0.006), \operatorname{LDL}(P=0.03)$, and TG $(P=0.006)$ between the two groups. This result was remained significant for fasting insulin $(P<0.001)$, HOMA-IR $(P<0.001)$ and TG $(P=0.04)$ after adjustment of weight, BMI, energy intake and physical activity levels.

In the post intervention, fasting insulin $(P<0.001)$, HOMA-IR $(P<0.001)$, total cholesterol $(P<0.001)$, LDL $(P<0.001), T G(P<0.001)$ and leptin $(P<0.001)$ decreased significantly in the intervention group. Also, adiponectin $(P<0.001)$ increased significantly after eight weeks vitamin B6 supplementation. The Placebo group showed no significant change after eight weeks $(P>0.05)$. No side effects from vitamin B6 supplementation were observed at the end of the study.

\section{Discussion:}

To the best our knowledge, this is the first randomized, double-blinded, controlled clinical trial to evaluate the effects of $80 \mathrm{mg} /$ day pyridoxine hydrochloride supplement on anthropometric measurements, body composition, visceral adiposity index, glycemic and lipidemic risk factors and serum levels of leptin and adiponectin in obese and overweight women. The current recommended daily amount (RDA) for B6 is $1.6 \mathrm{mg}$ for adults over 19(27). No adverse effects have been seen from the consumption of B6 food sources. Although some studies have shown severe sensory neuropathy due to treatment with 2-6 g / day pyridoxine hydrochloride (28). The amount of upper limit for this vitamin is $100 \mathrm{mg} /$ day (29).

Results of the present study showed that 8-week consumption of pyridoxine hydrochloride reduced BMI and improved body composition compared with the placebo.

In some studies the effects of pyridoxine on calcium ion signaling have been observed that increases lipolysis and decreases fatty acid synthesis (10-12) Zemel et al (2013) studied the effects of a leucine and pyridoxine-containing nutraceutical on body weight and composition in obese subjects. They recently demonstrated leucine to modulate energy partitioning between adipose tissue and muscle. Further, leucine exhibits a synergy with B6, resulting in reduced adipocyte lipid storage coupled with increased muscle fat oxidation and insulin sensitivity, and reduced oxidative and inflammatory stress (15). They found that this nutraceutical combination improve oxidative capacity and thereby significantly augments weight and fat loss (30). Pyridoxal phosphate inhibits adipocyte $\mathrm{Ca} 2+$ influx in vitro, resulting in significant decreases in adipocyte fatty acid synthase expression and activity and corresponding reductions in adipocyte triglyceride content(31) because $\mathrm{Ca} 2+$ signaling coordinately stimulates fatty acid synthase activity and inhibits lipolysis in adipocytes(32-36) 
Our results showed that pyridoxine hydrochloride had beneficial effects on lipid profile.This effect of vitamin B6 have been shown before (17-19). Pyridoxine supplementation decreased plasma total cholesterol, LDL cholesterol and triglycerides; and reduced HDL cholesterol (17).Also vitamin B6 supplementation was associated with a significant reduction in total cholesterol and HDL cholesterol (18).

We observed significant reduction in fasting insulin and HOMA-IR. In some studies, it has also been shown to decrease fasting blood glucose $(13,22)$ and insulin resistance $(13-16)$.

Unoki-Kubota et al (2010) examined pyridoxamine supplementation, an inhibitor of (Advanced glycation end products) AGE formation could ameliorate insulin resistance in obese mice with type 2 diabetes. In this study administration of pyridoxamine decreased fasting insulin levels and improved insulin sensitivity in mice (14).

Spellacy et al in 1976 decided to investigate the role of vitamin B6 (pyridoxine) treatment in women with gestational diabetes. This study demonstrated that in one small group treatment with vitamin B6 resulted in an improvement in glucose tolerance and reduced plasma insulin (37). In 2009, Hagiwara et al, conducted a study to investigate the effects of pyridoxamine on glucose intolerance and obesity in mice. It showed that the antioxidative effect of pyridoxamine is associated with improvement of glucose intolerance and obesity in mice fed a high-fat diet. They said that pyridoxamine may be useful in the treatment of the obesity-associated metabolic syndrome(21).Moreover they recently demonstrated the effect of pyridoxamine, an AGE inhibitor, on improvement of glucose intolerance in type 2 diabetes mellitus mice(38).

In our study leptin decreased and adiponectin increased significantly in the pyridoxine hydrochloride group. Maessen et al(2016) reported that pyridoxamine (PM) intervention prevents body weight gain, improves metabolic characteristics (Fasting plasma glucose, cholesterol, insulin, and leptin levels), prevents mild vascular dysfunction and reduces lipid content of liver in (High fat diet)HFD-Induced obese mice. Altogether, these findings highlight the potential of PM to serve as an intervention strategy in obesity (39).

The design of the study, inclusion and exclusion criteria, controlling for covariates, and repeated assessment of dietary components are amongst the strengths of this study. The randomization method distributes fairly the unknown confounding factors between the intervention and control groups. We also used double-blind method to minimize selection and information biases. There are some limitations pertinent to this trial, and we had a few lost to follow-up that prevented us to do intention-to-treat analysis. Further studies with larger sample sizes, longer duration and different dosages of pyridoxine hydrochloride are recommended. Although the participants were asked to maintain their usual diet especially food sources of vitamin B6 during the study, the results may have been affected by unreported or poor compliance. There was not any report of complication or side effect due to intake of pyridoxine hydrochloride supplement by the participants during the study. 


\section{Conclusion:}

This study demonstrated that 8-week supplementation with pyridoxine hydrochloride can reduce BMI and improve body composition and biochemical factors associated with obesity. Pyridoxine hydrochloride may have protective effects against obesity.

\section{Abbreviations}

\section{BMI}

Body mass index

$\mathrm{Cl}$

Confidence interval

HOMA-IR

Homeostasis model assessment of insulin resistance

WC

Waist circumference

WHR

Waist-to-hip circumference ratio

IPAQ

International Physical Activity Questionnaire

MET

To metabolic equivalent

VAl

Visceral adiposity index

FBS

Fast blood sugar

TC

Total Cholestrol

HDL

High density lipoprotein

LDL

low density lipoprotein

TG

Triglycerides

ELISA

Enzyme linked immune sorbent assay

\section{Declarations}

Ethics approval and consent to participate: 
The trial was approved by the Ethics Committee of Ahvaz Jundishapur University of Medical Sciences (reference number: ir.ajums.rec.1394.254). After explaining the projects, we requested each participant to complete the consent form.

\section{Consent for publication:}

Not applicable.

\section{Availability of data and materials:}

The datasets used and/or analysed during the current study are available from the corresponding author on reasonable request.

\section{Competing interests:}

The authors declare that they have no competing interests.

\section{Funding:}

This study was supported by a grant from the Ahvaz Jundishapur University of Medical Sciences, Iran (Grant Number: NRC9711).These funding and supporting sources have no role in the design of the study and collection, analysis and interpretation of data or in writing the manuscript.

\section{Authors' contributions:}

$\mathrm{FM}, \mathrm{FH}$ and $\mathrm{MM}$ designed the research; FM and FH contributed to acquisition of data. $\mathrm{MZ}$ was involved in biochemical analysis. MhH did statistical analysis. FM and FH wrote the manuscript. FH and FM contributed to critical revision of the manuscript. Each author has participated sufficiently in the work to take public responsibility for appropriate portions of the content. All authors read and approved the final manuscript

\section{Acknowledgements:}

The present study was a part of the master's thesis of Fatemeh Mirzaee. We thank the participants for their assistance in the biochemical and nutritional evaluation and Ahvaz Jundishapur University of Medical Sciences for the grant support and Health Research Institute, Diabetes Research Center, Ahvaz Jundishapur University of Medical Sciences for its role in some biochemical analysis.

\section{References}

1-http://new.who.int/news-room/fact-sheets/detail/obesity-and-overweight

2-Lysen LK, Israel DA. Nutrition in weight management. Krause's food and the nutrition care process. 2012; 13:462-88. 
3-Upadhyay J, Farr O, Perakakis N, Ghaly W, Mantzoros C. Obesity as a Disease. The Medical Clinics of North America. 2018 Jan;102(1):13-33. DOI: 10.1016/j.mcna.2017.08.004.

Top of Form

4-Haidari F, Samadi M, Mohammadshahi M, Jalali MT, Engali KA. Energy restriction combined with green coffee bean extract affects serum adipocytokines and the body composition in obese women. Asia Pac J Clin Nutr. 2017;26(6):1048-1054. doi:10.6133/apjen.022017.03

5-Spinneker A, Sola R, Lemmen V, Castillo MJ, Pietrzik K, González-Gross M. Vitamin B6 status, deficiency and its consequences-an overview. Nutr Hosp. 2007;22(1):7-24.

6-Lee Gallagher M. The nutrients and their metabolism. Krause's food and the nutrition care process. $2012 ; 13: 74-88$

7-Kleijnen J. Knipschild P. Niacin and vitamin B6 in mental functioning: a review of controlled trials in humans. Biol Psychiatry1991; 29:931-941.

8-Mikkelsen K, Stojanovska L, Prakash M, Apostolopoulos V. The effects of vitamin B on the immune/cytokine network and their involvement in depression. Maturitas. 2017 Feb 1; 96:58-71.

9-Konarzewska B, Stefańska E, Wendołowicz A, Cwalina U, Golonko A, Małus A, Kowzan U, Szulc A, Rudzki L, Ostrowska L. Visceral obesity in normal-weight patients suffering from chronic schizophrenia. BMC psychiatry. 2014 Dec; 14(1):35.

10-Lal, K.J.; Sharma, S.K.; Dakshinamurti, K. Regulation of calcium influx into vascular smooth muscle by vitamin B6. Clin. Exp. Hypertens. 1993, 15, 489-500.

11-Dakshinamurti, K.; Lal, K.J.; Ganguly, P.K. Hypertension, calcium channel and pyridoxine (vitamin B6). Mol. Cell Biochem. 1998, 188, 137-148.

12-Vasdev, S. Dietary vitamin B6 supplementation attenuates hypertension in spontaneously hypertensive rats. Mol. Cell Biochem. 1999, 200, 155-162

13-Liu Z, Li P, Zhao ZH, Zhang Y, Ma ZM, Wang SX. Vitamin b6 prevents endothelial dysfunction, insulin resistance, and hepatic lipid accumulation in apoe -/- mice fed with high-fat diet. Journal of diabetes research. 2016; 2016.

14-Unoki-Kubota H, Yamagishi SI, Takeuchi M, Bujo H, Saito Y. Pyridoxamine, an inhibitor of advanced glycation end product (AGE) formation ameliorates insulin resistance in obese, type 2 diabetic mice. Protein and peptide letters. 2010 Sep 1; 17(9):1177-81.

15-Zemel MB, Bruckbauer A. Effects of a leucine and pyridoxine-containing nutraceutical on fat oxidation, and oxidative and inflammatory stress in overweight and obese subjects. Nutrients. 2012 Jun 15; 
4(6):529-41.

16-Spellacy WN, Buhi WC, Birk SA. Vitamin B6 treatment of gestational diabetes mellitus: studies of blood glucose and plasma insulin. American journal of obstetrics and gynecology. 1977 Mar 15; 127(6):599602.

17-de Gómez Dumm NT, Giammona AM, Touceda LA. Variations in the lipid profile of patients with chronic renal failure treated with pyridoxine. Lipids in Health and Disease. 2003 Dec; 2(1):7.

18-Hlais S, Reslan DR, Sarieddine HK, Nasreddine L, Taan G, Azar S, Obeid OA. Effect of Lysine, Vitamin B6, and Carnitine Supplementation on the Lipid Profile of Male Patients With Hypertriglyceridemia: A 12Week, Open-Label, Randomized, Placebo-Controlled Trial. Clinical therapeutics. 2012 Aug 1; 34(8):167482.

19-VIRK, RICKY S., et al. Effect of vitamin B-6 supplementation on fuels, catecholamines, and amino acids during exercise in men. Medicine and science in sports and exercise, 1999, 31.3: 400-408.

20-Tambasco-Studart M, Titiz O, Raschle T, Forster G, Amrhein N,Fitzpatrick TB (2005) Vitamin B6 biosynthesis in higher plants.Proc Natl Acad Sci U S A 102(38):13687-13692

21-Hagiwara S, Gohda T, Tanimoto M, Ito T, Murakoshi M, Ohara I, Yamazaki T, Matsumoto M, Horikoshi S, Funabiki K, Tomino Y. Effects of pyridoxamine (K-163) on glucose intolerance and obesity in high-fat diet C57BL/6J mice. Metabolism-Clinical and Experimental. 2009 Jul 1; 58(7):934-45.

22-Abraham PM, Kuruvilla KP, Mathew J, Malat A, Joy S, Paulose CS. Alterations in hippocampal serotonergic and INSR function in streptozotocin induced diabetic rats exposed to stress: neuroprotective role of pyridoxine and Aegle marmelose. Journal of biomedical science. 2010 Dec; 17(1):78.

23-Wolin KY, Heil DP, Askew S, Matthews CE, Bennett GG. Validation of the International Physical Activity Questionnaire-Short among Blacks. J Phys Act Health. 2008; 5:746-60.

24-Amato MC, Giordano C. Visceral adiposity index: an indicator of adipose tissue dysfunction. Int J Endocrinol. 2014;2014(730827):14.

25-Chen Y, Zhang X, Pan B, Jin X, Yao H, Chen B, Zou Y, Ge J, Chen H. A modified formula for calculating lowdensitylipoprotein cholesterol values. Lipids in Health and Disease. 2010; 9:52.

26-Mahmoud AM, Ashour MB, Abdel-Moneim A, Ahmed OM. Hesperidin and naringin attenuate hyperglycemia-mediated oxidative stress and proinflammatory cytokine production in high fat fed/streptozotocin-induced type 2 diabetic rats. J Diabetes Complications 2012; 26:483-90.

27-D-A-CH: Reference values for nutrient intakes.Umschau/Braus. Pages. Frankfurt am Main. 1. ed. 2000. 
28-Bear RL. Cutaneous skin changes probably due to pyridoxine abuse. J Am Acad Dermatol 1984; 10:527-528.

29-Food and Nutriton Board. Dietary reference intakes for thiamine, riboflavin, niacin, vitamin B6, folate, vitamin B12, pantothenic acid, biotin, and choline. National Academy Press. Washington DC, 1998.

30-Zemel MB, Bruckbauer A. Effects of a leucine and pyridoxine-containing nutraceutical on body weight and composition in obese subjects. Diabetes Metab Syndr Obes. 2013;6:309-315. Published 2013 Aug 23. doi:10.2147/DMSO.S49623.

31-Zemel MB, Bruckbauer A. Effects of a leucine and pyridoxine-containing nutraceutical on fat oxidation, and oxidative and inflammatory stress in overweight and obese subjects. Nutrients. 2012; 4:529-541.

32-Xue B, Zemel M. Relationship between human adipose tissue agouti and fatty acid synthase (FAS). J Nutr. 2000; 130:2478-2481.

33- Kim JH, Kiefer LL, Woychik RP, Wilkison WO, Truesdale A, Ittoop O, Willard D, Nichols J, Zemel MB: Agouti regulation of intracellular calcium. Role of melanocortin receptor. Am J Physiol 272: E379E384, 1997.

34-Xue B, Greenberg A, Kraemer F, Zemel M. Mechanism of intracellular calcium ([Ca2+]i) inhibition of lipolysis in human adipocytes. FASEB J. 2001; 15:2527-2529.

35-Xue B. The agouti gene product inhibits lipolysis in human adipocytes via a Ca2+-dependent mechanism. FASEB J. 1998; 12:1391-1396.

36-Shi H, Moustaid-Moussa N, Wilkison W, Zemel M. Role of the sulfonylurea receptor in regulating human adipocyte metabolism. FASEB J. 1999; 13:1833-1838.

37-Spellacy WN, Buhi WC, Birk SA. Vitamin B6 treatment of gestational diabetes mellitus: studies of blood glucose and plasma insulin. Am J Obstet Gynecol. 1977; 127(6):599-602.

38-Tanimoto M, Gohda T, Kaneko S, Hagiwara S, Murakoshi M, Aoki T, et al. Effect of pyridoxamine (K163), an inhibitor of advanced glycation end products, on type 2 diabetic nephropathy in KK-A(y)/Ta mice. Metabolism 2007; 56:160-7.

39-Maessen DE, Brouwers O, Gaens KH, et al. Delayed Intervention With Pyridoxamine Improves Metabolic Function and Prevents Adipose Tissue Inflammation and Insulin Resistance in High-Fat DietInduced Obese Mice. Diabetes. 2016; 65(4):956-966.

\section{Tables}

Table 1. Demographic and anthropometric characteristics of the study population 


\begin{tabular}{|c|c|c|c|c|c|}
\hline Variable & & pyridoxine hydrochloride group $(\mathrm{N}=22)$ & Placebo group $(\mathbb{N}=22)$ & $p 1^{*}$ & $p 2^{* 8}$ \\
\hline Age (year) & & $33.86 \pm 9.86$ & $30.90 \pm 12.32$ & 0.22 & - \\
\hline Height (cm) & & $159.04 \pm 5.97$ & $160.02 \pm 5.09$ & 0.48 & - \\
\hline Weight (kg) & $\begin{array}{l}\text { Week } 0 \\
\text { Week } 8 \\
p 3^{* 8 *}\end{array}$ & $\begin{array}{l}75.95 \pm 11.64 \\
74.88 \pm 11.41 \\
0.01\end{array}$ & $\begin{array}{l}77.22 \pm 8.00 \\
77.55 \pm 8.13 \\
0.23\end{array}$ & $\begin{array}{l}0.26 \\
0.23\end{array}$ & - \\
\hline $\mathrm{BMI}(\mathrm{kg} / \mathrm{m} 2)$ & $\begin{array}{l}\text { Week } 0 \\
\text { Week } 8 \\
p 3^{* 8 *}\end{array}$ & $\begin{array}{l}30.04 \pm 4.52 \\
29.61 \pm 4.43 \\
0.009\end{array}$ & $\begin{array}{l}30.20 \pm 3.20 \\
34.63 \pm 13.57 \\
0.095\end{array}$ & $\begin{array}{l}0.42 \\
0.09\end{array}$ & - \\
\hline Fat mass $(\mathrm{kg})$ & $\begin{array}{l}\text { Week } 0 \\
\text { Week } 8 \\
p 3^{* 8 *}\end{array}$ & $\begin{array}{l}33.96 \pm 9.11 \\
32.75 \pm 8.32 \\
0.003\end{array}$ & $\begin{array}{l}35.51 \pm 5.99 \\
36.22 \pm 5.87 \\
0.223\end{array}$ & $\begin{array}{l}0.13 \\
0.02\end{array}$ & $\begin{array}{l}0.91 \\
0.000\end{array}$ \\
\hline Muscle mass (kg) & $\begin{array}{l}\text { Week } 0 \\
\text { Week } 8 \\
p 3 * * 8\end{array}$ & $\begin{array}{l}18.09 \pm 2.16 \\
18.26 \pm 2.28 \\
0.291\end{array}$ & $\begin{array}{l}17.76 \pm 2.35 \\
17.61 \pm 2.14 \\
0.733\end{array}$ & $\begin{array}{l}0.39 \\
0.15\end{array}$ & $\begin{array}{l}0.47 \\
0.23\end{array}$ \\
\hline Fat mass/Muscle mass & $\begin{array}{l}\text { Week } 0 \\
\text { Week } 8 \\
p 3^{8 * *}\end{array}$ & $\begin{array}{l}1.87 \pm 0.42 \\
1.79 \pm 0.37 \\
0.005\end{array}$ & $\begin{array}{l}2.02 \pm 0.36 \\
2.06 \pm 0.32 \\
0.709\end{array}$ & $\begin{array}{l}0.133 \\
0.005\end{array}$ & $\begin{array}{l}0.94 \\
0.000\end{array}$ \\
\hline $\mathrm{WC}(\mathrm{cm})$ & $\begin{array}{l}\text { Week } 0 \\
\text { Week } 8 \\
\text { p3**8 }\end{array}$ & $\begin{array}{l}98.36 \pm 21.88 \\
96.91 \pm 21.86 \\
0.005\end{array}$ & $\begin{array}{l}94.59 \pm 5.89 \\
95.09 \pm 6.09 \\
0.065\end{array}$ & $\begin{array}{l}1.000 \\
0.46\end{array}$ & $\begin{array}{c}0.06 \\
0.09\end{array}$ \\
\hline $\mathrm{WHR}(\mathrm{cm})$ & $\begin{array}{l}\text { Week } 0 \\
\text { Week } 8 \\
p 3^{* * 8}\end{array}$ & $\begin{array}{l}0.90 \pm 0.16 \\
0.89 \pm 0.16 \\
0.073\end{array}$ & $\begin{array}{l}0.86 \pm 0.06 \\
0.86 \pm 0.06 \\
0.145\end{array}$ & $\begin{array}{l}0.69 \\
0.92\end{array}$ & $\begin{array}{l}0.78 \\
0.91\end{array}$ \\
\hline $\begin{array}{l}\text { Visceral Adiposity } \\
\text { Index }\end{array}$ & $\begin{array}{l}\text { Week } 0 \\
\text { Week } 8 \\
\text { p3*** }\end{array}$ & $\begin{array}{l}3.87 \pm 2.19 \\
3.25 \pm 1.72 \\
0.001\end{array}$ & $\begin{array}{l}4.12 \pm 1.86 \\
3.89 \pm 1.79 \\
0.223\end{array}$ & $\begin{array}{l}0.25 \\
0.11\end{array}$ & $\begin{array}{l}0.53 \\
0.03\end{array}$ \\
\hline $\begin{array}{l}\text { IPAQ (metabolic } \\
\text { Equivalent of } \\
\text { task-min/wk) }\end{array}$ & $\begin{array}{l}\text { Week } 0 \\
\text { Week } 8 \\
\text { p3*** }\end{array}$ & $\begin{array}{l}2096 \pm 12.44 \\
2102 \pm 23.24 \\
0.34\end{array}$ & $\begin{array}{l}2096 \pm 14.34 \\
2094 \pm 15.22 \\
0.39\end{array}$ & $\begin{array}{l}0.90 \\
0.24\end{array}$ & - \\
\hline
\end{tabular}

Table 2. Dietary intake at the baseline, mid and end of the study in two groups. 


\begin{tabular}{|c|c|c|c|c|}
\hline Variable & & pyridoxine hydrochloride group $(\mathrm{N}=22)$ & Placebo group $(\mathrm{N}=22)$ & $\mathrm{pl}^{*}$ \\
\hline Energy (kcal) & $\begin{array}{c}\text { Week 0 } \\
\text { Week } 4 \\
\text { Week } 8 \\
p 2^{24}\end{array}$ & $\begin{array}{l}1709 \pm 150 \\
1800=266 \\
1678 \pm 246 \\
0.16\end{array}$ & $\begin{array}{l}1708 \pm 187 \\
1698 \pm 211 \\
1758 \pm 202 \\
0.41\end{array}$ & $\begin{array}{l}0.92 \\
0.31 \\
0.32\end{array}$ \\
\hline Protein (percent of energy) & $\begin{array}{c}\text { Week } 0 \\
\text { Week } 4 \\
\text { Week } 8 \\
p 2^{* 4}\end{array}$ & $\begin{array}{l}18 \pm 2.31 \\
17 \pm 2.75 \\
18 \pm 1.98 \\
0.72\end{array}$ & $\begin{array}{l}17 \pm 1.88 \\
18 \pm 2.17 \\
17 \pm 2.02 \\
0.06\end{array}$ & $\begin{array}{l}0.64 \\
0.24 \\
0.06\end{array}$ \\
\hline $\begin{array}{l}\text { Carbohydrate (percent of } \\
\text { energy) }\end{array}$ & $\begin{array}{c}\text { Week } 0 \\
\text { Week } 4 \\
\text { Week } 8 \\
p 2^{* 4}\end{array}$ & $\begin{array}{l}53 \pm 2.51 \\
53 \pm 3.17 \\
54=2.29 \\
0.78\end{array}$ & $\begin{array}{l}53 \pm 2.63 \\
54=2.22 \\
53 \pm 2.12 \\
0.12\end{array}$ & $\begin{array}{l}0.51 \\
0.20 \\
0.06\end{array}$ \\
\hline Fat (percent of energy) & $\begin{array}{c}\text { Week } 0 \\
\text { Week } 4 \\
\text { Week } 8 \\
p 2^{* 4}\end{array}$ & $\begin{array}{l}28=2.71 \\
27=3.33 \\
27=3.15 \\
0.60\end{array}$ & $\begin{array}{l}28 \pm 2.46 \\
28 \pm 3.05 \\
29 \pm 3.35 \\
0.38\end{array}$ & $\begin{array}{l}0.43 \\
0.29 \\
0.16\end{array}$ \\
\hline SFA (g) & $\begin{array}{c}\text { Week } 0 \\
\text { Week } 4 \\
\text { Week } 8 \\
p 2^{* 4}\end{array}$ & $\begin{array}{l}13 \pm 1.54 \\
12 \pm 1.39 \\
12=1.55 \\
0.38\end{array}$ & $\begin{array}{l}12=1.61 \\
12=1.50 \\
13=1.43 \\
0.41\end{array}$ & $\begin{array}{l}0.10 \\
0.76 \\
0.07\end{array}$ \\
\hline MUFA (g) & $\begin{array}{c}\text { Week } 0 \\
\text { Week } 4 \\
\text { Week } 8 \\
p 2^{* 4}\end{array}$ & $\begin{array}{l}13 \pm 1.59 \\
13 \pm 1.44 \\
14=1.67 \\
0.17\end{array}$ & $\begin{array}{l}13=1.27 \\
13 \pm 1.37 \\
12 \pm 1.32 \\
0.09\end{array}$ & $\begin{array}{l}0.52 \\
0.34 \\
0.06\end{array}$ \\
\hline PUFA (g) & $\begin{array}{c}\text { Week } 0 \\
\text { Week } 4 \\
\text { Week } 8 \\
p 2^{* 4}\end{array}$ & $\begin{array}{l}15 \pm 1.36 \\
16 \pm 1.27 \\
18 \pm 1.74 \\
0.82\end{array}$ & $\begin{array}{l}14 \pm 1.72 \\
17 \pm 1.57 \\
16 \pm 1.31 \\
0.91\end{array}$ & $\begin{array}{l}0.82 \\
0.51 \\
0.63\end{array}$ \\
\hline Cholesterol (g) & $\begin{array}{c}\text { Week } 0 \\
\text { Week } 4 \\
\text { Week } 8 \\
p 2^{*+}\end{array}$ & $\begin{array}{l}133 \pm 15.12 \\
132 \pm 23.49 \\
122 \pm 9.99 \\
0.09\end{array}$ & $\begin{array}{l}125 \pm 11.74 \\
127 \pm 17.49 \\
121 \pm 15.38 \\
0.17\end{array}$ & $\begin{array}{l}0.06 \\
0.77 \\
0.51\end{array}$ \\
\hline Fibre (g) & $\begin{array}{c}\text { Week } 0 \\
\text { Week } 4 \\
\text { Week } 8 \\
p 2^{*+}\end{array}$ & $\begin{array}{l}10.39 \pm 2.16 \\
10.09 \pm 2.03 \\
10.25 \pm 2.05 \\
0.49\end{array}$ & $\begin{array}{l}11.01 \pm 1.92 \\
10.21=2.27 \\
10.27=2.06 \\
0.13\end{array}$ & $\begin{array}{l}0.63 \\
0.74 \\
0.81\end{array}$ \\
\hline $\mathrm{B} 6(\mathrm{mg})$ & $\begin{array}{c}\text { Week } 0 \\
\text { Week } 4 \\
\text { Week } 8 \\
p 2^{*+}\end{array}$ & $\begin{array}{l}1.87 \pm 0.72 \\
1.71 \pm 0.75 \\
1.89 \pm 0.48 \\
0.46\end{array}$ & $\begin{array}{l}1.90 \pm 0.46 \\
2.07 \pm 0.57 \\
2.21 \pm 0.46 \\
0.14\end{array}$ & $\begin{array}{l}0.65 \\
0.10 \\
0.06\end{array}$ \\
\hline
\end{tabular}

SFA: saturated fatty acid; MUFA: monounsaturated fatty acid; PUFA: polyunsaturated fatty acid. $\dagger$ Mean $=$ standard deviation ( $95 \%$ confidence interval). $p 1^{*}$ : are results from Mann-Whitney U test.

$p 2^{* *}$ : are results from Friedman test.

Table 3. Effect of pyridoxine hydrochloride supplement on FBS, fasting insulin and lipid profile in the study population. 


\begin{tabular}{|c|c|c|c|c|c|}
\hline Variable & & pyridoxine hydrochloride group $(\mathrm{N}=22)$ & Placebo group $(\mathrm{N}=22)$ & $p 1^{*}$ & $p 2^{4 *}$ \\
\hline FBS (mg/dL) & $\begin{array}{l}\text { Week } 0 \\
\text { Week } 8 \\
p 3^{* * 4}\end{array}$ & $\begin{array}{l}82.09 \pm 6.76 \\
83.22 \pm 4.91 \\
0.41\end{array}$ & $\begin{array}{l}85.40 \pm 8.56 \\
87.54=9.70 \\
0.19\end{array}$ & $\begin{array}{l}0.07 \\
0.06\end{array}$ & $\begin{array}{l}0.18 \\
0.43\end{array}$ \\
\hline Fasting insulin ( $\mathrm{u} / \mathrm{mL}$ ) & $\begin{array}{l}\text { Week } 0 \\
\text { Week } 8 \\
p 3^{* 04}\end{array}$ & $\begin{array}{l}11.73=1.30 \\
10.28 \pm 1.03 \\
0.000\end{array}$ & $\begin{array}{l}12.15 \pm 1.23 \\
12.20 \pm 1.23 \\
0.728\end{array}$ & $\begin{array}{l}0.21 \\
0.000\end{array}$ & $\begin{array}{l}0.57 \\
0.000\end{array}$ \\
\hline HOMA-IR & $\begin{array}{l}\text { Week } 0 \\
\text { Week } 8 \\
p 3 * * *\end{array}$ & $\begin{array}{l}2.34 \pm .29 \\
1.92 \pm .20 \\
0.000\end{array}$ & $\begin{array}{l}2.53 \pm .40 \\
2.60 \pm .40 \\
0.910\end{array}$ & $\begin{array}{l}0.07 \\
0.000\end{array}$ & $\begin{array}{l}0.31 \\
0.000\end{array}$ \\
\hline Total cholesterol (mg/dL) & $\begin{array}{l}\text { Week } 0 \\
\text { Week } 8 \\
p 3^{4 *+\infty}\end{array}$ & $\begin{array}{l}161.59 \pm 21.83 \\
148.90 \pm 18.45 \\
0.000\end{array}$ & $\begin{array}{l}166.63 \pm 26.48 \\
167.50 \pm 24.16 \\
0.643\end{array}$ & $\begin{array}{c}0.664 \\
0.006\end{array}$ & $\begin{array}{l}0.939 \\
0.066\end{array}$ \\
\hline $\mathrm{LDL}(\mathrm{mg} / \mathrm{dL})$ & $\begin{array}{l}\text { Week } 0 \\
\text { Week } 8 \\
p 3^{4+4}\end{array}$ & $\begin{array}{l}97.09 \pm 19.41 \\
85.78 \pm 17.49 \\
0.000\end{array}$ & $\begin{array}{l}100.63 \pm 22.51 \\
98.73=22.24 \\
0.355\end{array}$ & $\begin{array}{l}0.54 \\
0.03\end{array}$ & $\begin{array}{l}0.97 \\
0.28\end{array}$ \\
\hline $\mathrm{HDL}$ (mg/dL) & $\begin{array}{l}\text { Week } 0 \\
\text { Week } 8 \\
p 3^{+44}\end{array}$ & $\begin{array}{l}47.09 \pm 6.05 \\
47.95 \pm 6.55 \\
0.45\end{array}$ & $\begin{array}{l}46.50=7.37 \\
47.86=7.51 \\
0.06\end{array}$ & $\begin{array}{l}0.64 \\
0.91\end{array}$ & $\begin{array}{l}0.88 \\
0.99\end{array}$ \\
\hline $\mathrm{TG}(\mathrm{mg} / \mathrm{dL})$ & $\begin{array}{l}\text { Week } 0 \\
\text { Week } 8 \\
p 3 * 4\end{array}$ & $\begin{array}{l}87.04 \pm 36.01 \\
75.86 \pm 32.44 \\
0.000\end{array}$ & $\begin{array}{l}97.50 \pm 36.35 \\
97.68 \pm 30.25 \\
0.615\end{array}$ & $\begin{array}{l}0.27 \\
0.006\end{array}$ & $\begin{array}{l}0.47 \\
0.04\end{array}$ \\
\hline
\end{tabular}

FBS: fasting blood sugar; LDL: low density lipoprotein; HDL: high density lipoprotein; TG: triglyceride; FFA: free fatty acid.

$\dagger$ Mean $=$ standard deviation ( $95 \%$ confidence interval).

$p 1^{*}$ : are results from Mamn-Whitney U test

$p 2^{\circ *}$ : are results from analysis of covariance in the adjusted models (adjusted for Weight, BMI, energy intake and physical activity).

$p 3^{\circ * 4}$ : are results from Wilcoxon's signature ranking test.

Table 4. Effect of pyridoxine hydrochloride supplement on leptin and adiponectin pre and post the intervention.

\begin{tabular}{|llllll|}
\hline Variable & & Pyridoxine hydrochloride group(N=22) & Placebo group(N=22) & $p 1^{*}$ & $p 2^{* *}$ \\
\hline Leptin (ng $\mathrm{mL}$ ) & Week 0 & $31.25 \pm 6.62$ & $28.75 \pm 4.35$ & 0.13 & 0.16 \\
& Week 8 & $25.66 \pm 6.12$ & $27.64 \pm 4.85$ & 0.18 & 0.23 \\
& $p 3^{*+*}$ & 0.000 & 0.094 & & 0.09 \\
Adiponectin ( $\mu \mathrm{g} / \mathrm{mL}$ ) & Week 0 & $7.40 \pm .79$ & $7.64 \pm .77$ & 0.41 & 0.11 \\
& Week 8 & $8.32 \pm 1.09$ & $7.66 \pm 1.17$ & 0.05 & \\
& $p^{* 4 *}$ & 0.000 & 0.970 & & \\
\hline
\end{tabular}

$\uparrow$ Mean $=$ standard deviation ( $95 \%$ confidence interval).

$p 1^{*}$ : are results from Mann-Whitney U test.

$p 2^{* *}$ : are results from analysis of covariance in the adjusted models (adjusted for Weight, BMI, energy intake and physical activity).

$p 3^{* * 4}$ : are results from Wilcoxon's gignature ranking test.

\section{Figures}




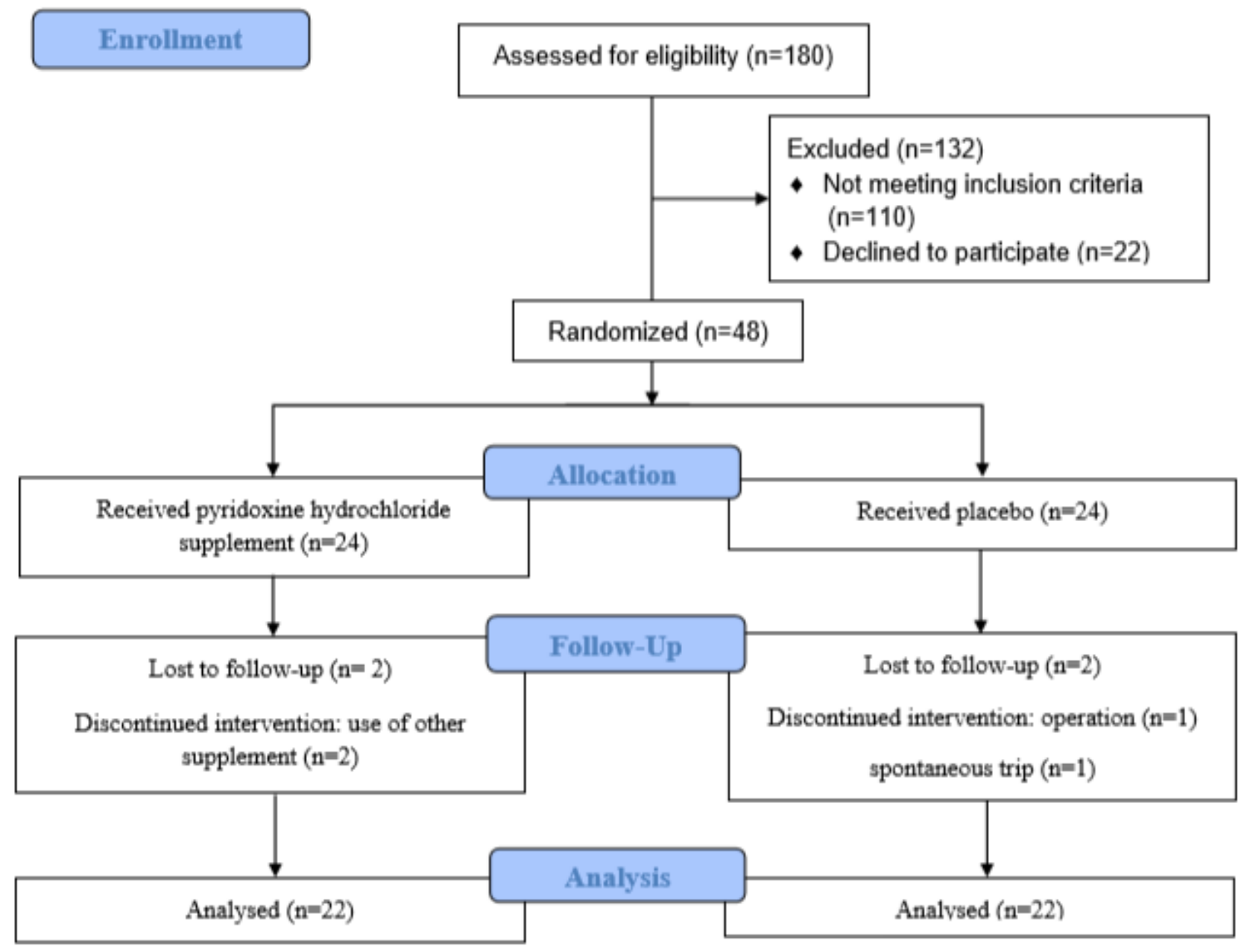

Figure 1

Flowchart of participant recruitment for the clinical trial of pyridoxine hydrochloride supplementation in obese and overweight women.

\section{Supplementary Files}

This is a list of supplementary files associated with this preprint. Click to download.

- CONSORT2010ChecklistMSWord.doc 